\title{
PATOLOGIAS ASFÁLTICAS DEVIDO AS OBRAS DE SUBSTITUIÇÃO DE REDES EM GURUPI-TO
}

\section{ARTIGO ORIGINAL}

SALES, Marcus Vinicius Ribeiro ${ }^{1}$

BARROS, Jefferson Alves ${ }^{2}$

SOUZA, Fernando Henrique Fernandes ${ }^{3}$

SALES, Marcus Vinicius Ribeiro. BARROS, Jefferson Alves. SOUZA, Fernando Henrique Fernandes. Patologias asfálticas devido as obras de substituição de redes em Gurupi-TO. Revista Científica Multidisciplinar Núcleo do Conhecimento. Ano 05, Ed. 10, Vol. 12, pp. 65-83. Outubro de 2020. ISSN: 2448-0959, Link de acesso: https://www.nucleodoconhecimento.com.br/engenharia-civil/patologias-

\section{asfalticas}

\section{RESUMO}

Na realidade do nosso país, é cada vez mais comum deparar-se com situações precárias que causam transtornos aos usuários nas ruas, assim como nas rodovias e avenidas. A avaliação da devida qualidade dos pavimentos, está relacionada a um conjunto de atividades que devem ser realizadas. Designando as propriedades e as qualidades dos resíduos do pavimento. A metodologia foi baseada em referências bibliográficas sobre o tema para obter embasamento teórico e através de visitas e registros de informações coletados ao longo da avenida. As coletas dos dados foram feitas em campo, ao longo de um percurso de aproximadamente 1500 metros na

\footnotetext{
${ }^{1}$ Graduação em Engenharia Civil.

${ }^{2}$ Graduação em Engenharia Civil.

${ }^{3}$ Orientador. Mestrado em Engenharia Civil. Especialização em Engenharia ambiental e indicadores de qualidade. Graduação em Engenharia Civil.
} 
Avenida Maranhão entre as ruas 12 e 20 no centro da cidade de Gurupi - TO, onde existem várias patologias asfáltica sobre a rede de esgoto e abastecimento. Com base nos dados coletados e com auxílio de um engenheiro que atua na área, foi possível levantar as informações complementares e necessárias para identificação das diversas patologias encontradas no local. Muitos dos defeitos encontrados indicam que as causas estão associadas principalmente aos processos de execução e envolvem a utilização incorreta dos materiais e também a falta de investimento para que seja feito um pavimento durável e de boa qualidade na qual deveria oferecer conforto aos motoristas que circulam por essa avenida.

Palavras-chave: Patologias, asfalto, avenida.

\section{INTRODUÇÃO}

De acordo com Aguiar (2012), o pavimento é uma estrutura destinada a resistir as ações das cargas e também proporcionar uma melhor condição de circulação aos veículos. Este deve oferecer conforto e segurança aos seus usuários, entretanto tem sido cada vez mais comum nas ruas e avenidas das cidades se deparar com patologias no asfalto, com isso a qualquer momento pode estar sujeito a cair em algum buraco, ou algo atípico.

Segundo Caldeira et al. (2018), essas patologias podem ser definidas como qualquer tipo de imperfeição na estrutura do pavimento, ou seja, qualquer coisa que se difira do que foi inicialmente planejado. E trazendo esse conceito das patologias para a pavimentação asfáltica, pode-se observar que grande parte das causas dessas patologias estão diretamente associadas aos carregamentos excessivos, a drenagem ineficiente, a má execução da fundação do pavimento e também devido aos desgastes naturais no longo prazo.

Pickett (2004) afirma que é necessário perceber os impactos ambientais antes de serem tomadas as medidas de reabilitação, para evitar problemas posteriormente. Com base nesses aspectos é elaborado um processo para a resolução dos danos através da criação e reparos dos pavimentos asfálticos. 
Para avaliar a devida qualidade de um pavimento é necessário observar as atividades que foram realizadas de forma conjunta, ou seja, observar tanto os materiais como também a maneira na qual estes materiais foram empregados. Sendo assim, é correto afirmar que agregados sem uma boa propriedade mecânica podem proporcionar risco e de tal maneira comprometer a qualidade do pavimento.

Bernucci (2008) ressalta que a forma das partículas dos agregados pode influenciar diretamente tanto na trabalhabilidade quanto na resistência contra esforços cisalhantes das misturas asfálticas e também pode alterar a energia mecânica necessária para que haja uma boa compactação no intuito de melhorar a densidade de determinado pavimento. Sendo assim, a melhor geometria a ser utilizada no asfalto é a com formato cúbico e não a lamelar.

Bernucci (2008) também afirma que os possíveis defeitos na superfície do pavimento podem aparecer precocemente tanto no médio quanto no longo prazo. Isso se dá ao fato de erros e inadequações, como erros de projeto, erros ou inadequações tanto na seleção quanto na dosagem ou até na produção dos materiais. Ele também destaca que esses erros induzem a redução da vida útil de projeto.

Diante dessa exposição, este trabalho tem o intuito de identificar as principais patologias presentes no pavimento da avenida Maranhão após a conclusão da manutenção e instalação das redes de abastecimento e esgoto na cidade, respectivamente. E também apresentar possíveis procedimentos para efeitos de correção e até mesmo prevenção dos problemas apresentados.

\section{REVISÃO DE LITERATURA}

Segundo Bernucci (2008), o pavimento é uma estrutura na qual possui diversas camadas cujas espessuras são finitas, sobrepostas e que são construídas sobre o subleito, ou seja, são destinadas a resistir aos esforços oriundos do tráfego de veículos e também das ações climáticas. 
A classificação dos pavimentos pode ser representada em três classes diferentes, são elas os pavimentos flexíveis, rígidos e os semirrígidos. A respeito dos pavimentos flexíveis o DER/SP-PRO (2006) diz que este é constituído por um revestimento asfáltico sobre a camada de base do solo estabilizado e que as camadas que constituem essa estrutura têm a função de absorção dos esforços provenientes do tráfego de veículos.

Bernucci et al. (2010), também afirmam que os pavimentos rígidos são aqueles cujo revestimento é constituído por placas de concreto de cimento Portland, ou seja, estes revestimentos possuem uma rigidez bem elevada em comparação as demais camadas e também possuem uma espessura fixa em função da resistência a flexão dessas placas.

As camadas do pavimento recebem as seguintes classificações conforme pode ser visualizado na Figura 1.

Figura 1 - Camadas de pavimentos rígidos e flexíveis
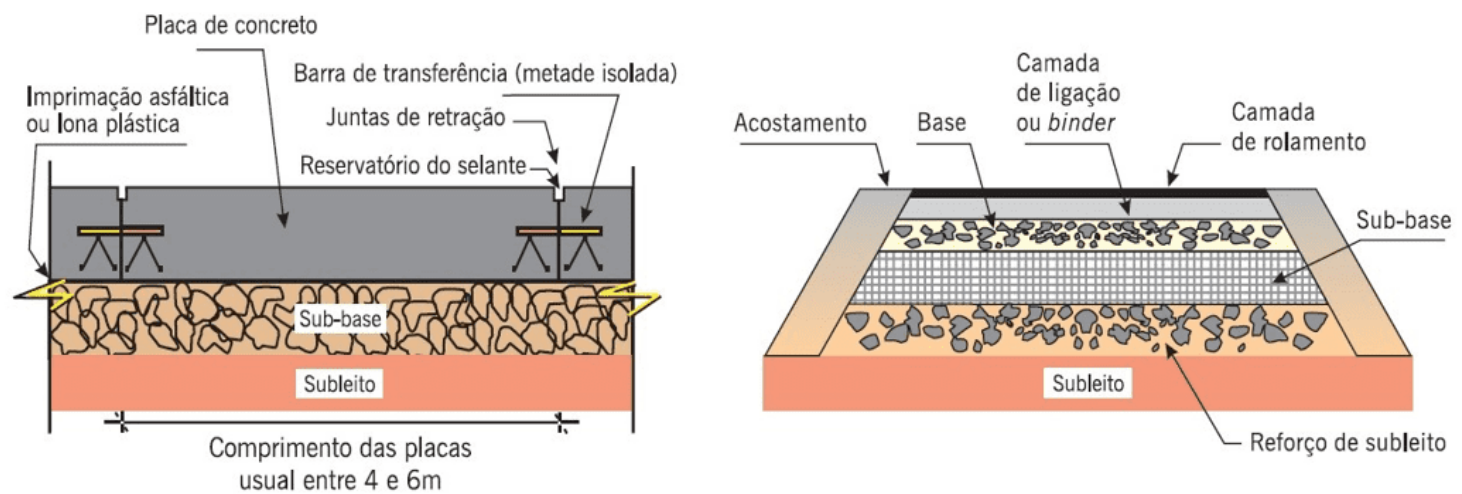

Fonte: Bernucci (2006)

Como pode ser observado anteriormente na Figura 1, as camadas do pavimento são divididas em revestimento, base, sub-base, reforço do subleito e o subleito. As definições de cada uma dessas camadas estão descritas abaixo.

Balbo (2016) diz que o revestimento do pavimento tem como função, receber cargas estáticas ou dinâmicas, sem que sofra grandes modificações elásticas, desagregação 
de componentes ou perda de compactação. Portanto, necessita ser composto de materiais bem aglutinados e dispostos de maneira para evitar sua movimentação horizontal.

Quanto a classificação dos revestimentos asfálticos, Balbo (2016) também afirma que estas em muitas ocasiões são divididas em duas ou mais camadas devido a procedimentos construtivos e custo. Dentre essas camadas, ele as específica como camada de rolamento, de ligação, nivelamento e a camada de reforço.

Já sobre as bases e sub-bases do pavimento, Balbo (2016) afirma que devido a necessidade de aliviar as pressões sobre as camadas de solo inferiores, surgem as camadas de bases e sub-bases, que também podem satisfazer papel importante na drenagem sub superficial dos pavimentos. E enfatiza que a função da base é distribuir os esforços para camadas inferiores.

Dando sequência as demais camadas, tem-se o reforço do subleito e o subleito. Balbo (2016) admite que se deve pensar em se executar sobre o subleito, uma vez que o mesmo apresenta uma pequena resistência aos esforços verticais que ocorreriam sobre a sua superfície, refletindo a melhor maneira de atribuir um reforço sobre a camada de superfície para que a fundação subjacente sofra menores pressões em compatibilidade com sua resistência.

E quanto ao subleito, Balbo (2016, p.37) diz que os esforços sobrepostos a suas superfícies serão aliviados em sua profundidade, logo, deve haver maior preocupação com seus estratos superiores que solicitam esforços com maior intensidade. $\mathrm{O}$ subleito será composto por "material natural consolidado e compactado (no caso de corte do corpo da estrada) ou por um material transportado e compactado, que é no caso dos aterros".

Quanto as patologias, o DNIT (2003) classifica as possíveis falhas no pavimento sobre as redes de esgoto, como falhas de desempenho funcional quanto desempenho estrutural. Sendo a primeira proveniente da má capacidade em satisfazer sua função principal, ou seja, não atender os termos de qualidade de rolamento. Já a segunda, 
em questão, se refere a sua integridade estrutural sem que apresente falhas significativas em suas camadas. Essa está amplamente relacionada com as fendas, deformações e desagregações da pavimentação.

Segundo Prestes (2001) essas classificações compreendem um conjunto de atividades destinadas à obtenção de dados, informações e parâmetros que permitam diagnosticar os problemas e interpretar o desempenho apresentado pelo pavimento, de modo que possa detectar as suas necessidades atuais e futuras de manutenções.

Devido a essas, diversas variações de casos de patologias surge a necessidade de realizar manutenções condizentes ao grau de instabilidade do pavimento, ou seja, acabam gerando novos gastos e também mais transtornos devido às obras de recuperação da via.

Conforme Guilherme et al. (2017) quando se trata do ponto de vista dos usuários, a funções funcionais do pavimento são as mais importantes, pois os defeitos na superfície do pavimento afetam diretamente o conforto e segurança, além dos custos operacionais.

\section{ESTUDO DE CASO}

A repavimentação ao longo da Avenida Maranhão entre as ruas 12 e 20 devido as obras de substituição de redes da companhia de abastecimento e esgoto da cidade, sob vias urbanas têm causado problemas constantes no pavimento devido à má execução. Estes tem gerado grande desconforto e insegurança aos usuários da via. Sendo assim serão apresentadas as principais causas e consequentemente, as soluções para as manifestações patológicas encontradas ao longo da via.

O percurso utilizado para estudo e análise das patologias pode ser observado abaixo na Figura 2. 
Figura 2 - Trecho da Avenida Maranhão estudado

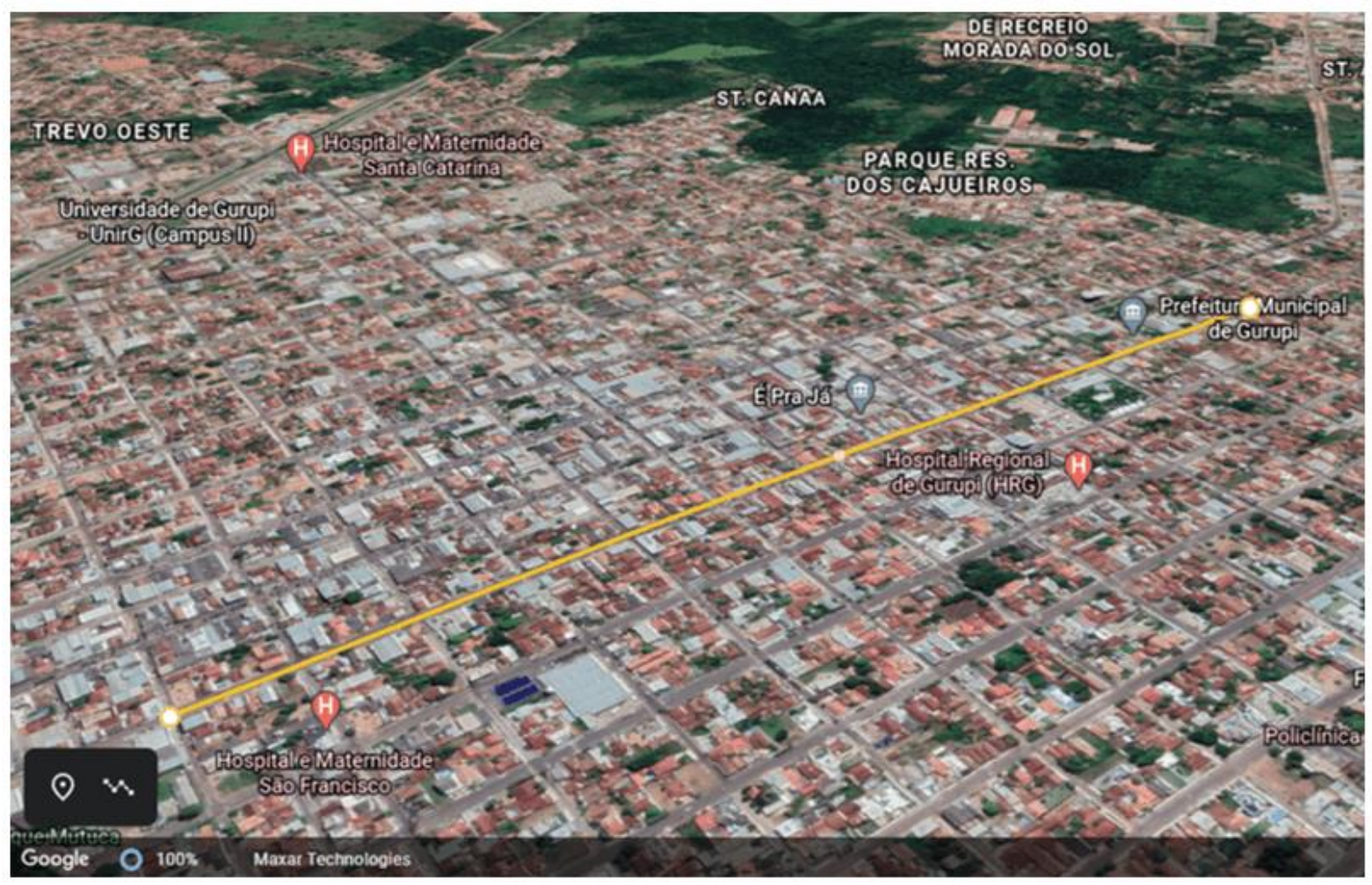

Fonte: Google Earth (2020)

Com base em estudos de referenciais teóricos e fotografias obtidas no local, foi possível observar a proporção desses defeitos com a finalidade de apresentar soluções preventivas e corretivas.

As soluções preventivas estão relacionadas de modo como deve ser executado o serviço a fim de evitar futuros aparecimentos das manifestações patológicas encontradas. E a solução corretiva consiste em como pode-se concertar os problemas já existentes.

O trabalho também relata sobre a importância do controle do grau de compactação dos materiais, da utilização de materiais adequados, de mão de obra qualificada e de equipamentos específicos para tais serviços a fim de obter um bom desempenho da repavimentação. 


\subsection{PATOLOGIAS EM PAVIMENTOS FLEXÍVEIS E SEMIRRÍGIDOS}

As patologias encontradas no pavimento são:

- Fendas;

- Afundamentos;

- Corrugações ou ondulações transversais;

- Exsudação;

- Desgaste ou desagregação;

- Buracos ou panelas;

\subsubsection{FENDAS}

Na norma DNIT 005/2003 - TER, as fendas são definidas como qualquer descontinuidade sobre a superfície do pavimento que conduza a aberturas de menor ou maior porte. Estas podem assumir tanto a feição de fissuras, como as de trincas isoladas longitudinais ou transversais e trincas interligadas como couro de jacaré ou tipo bloco. Essas fendas podem ser classificadas em FC-1, FC-2 e FC-3. Além disso, as fendas FC-3 apresentam erosão nas bordas (BRASIL, 2003).

As fendas encontradas sobre o pavimento asfáltico da avenida Maranhão podem ser vistas em variadas escalas ao longo de toda sua extensão, sendo muita destas expostas sobre remendos de reparos anteriores.

Essas manifestações patológicas encontradas no local podem ser observadas logo abaixo na Figura 3. 
Figura 3 - Fendas sobre remendos na avenida

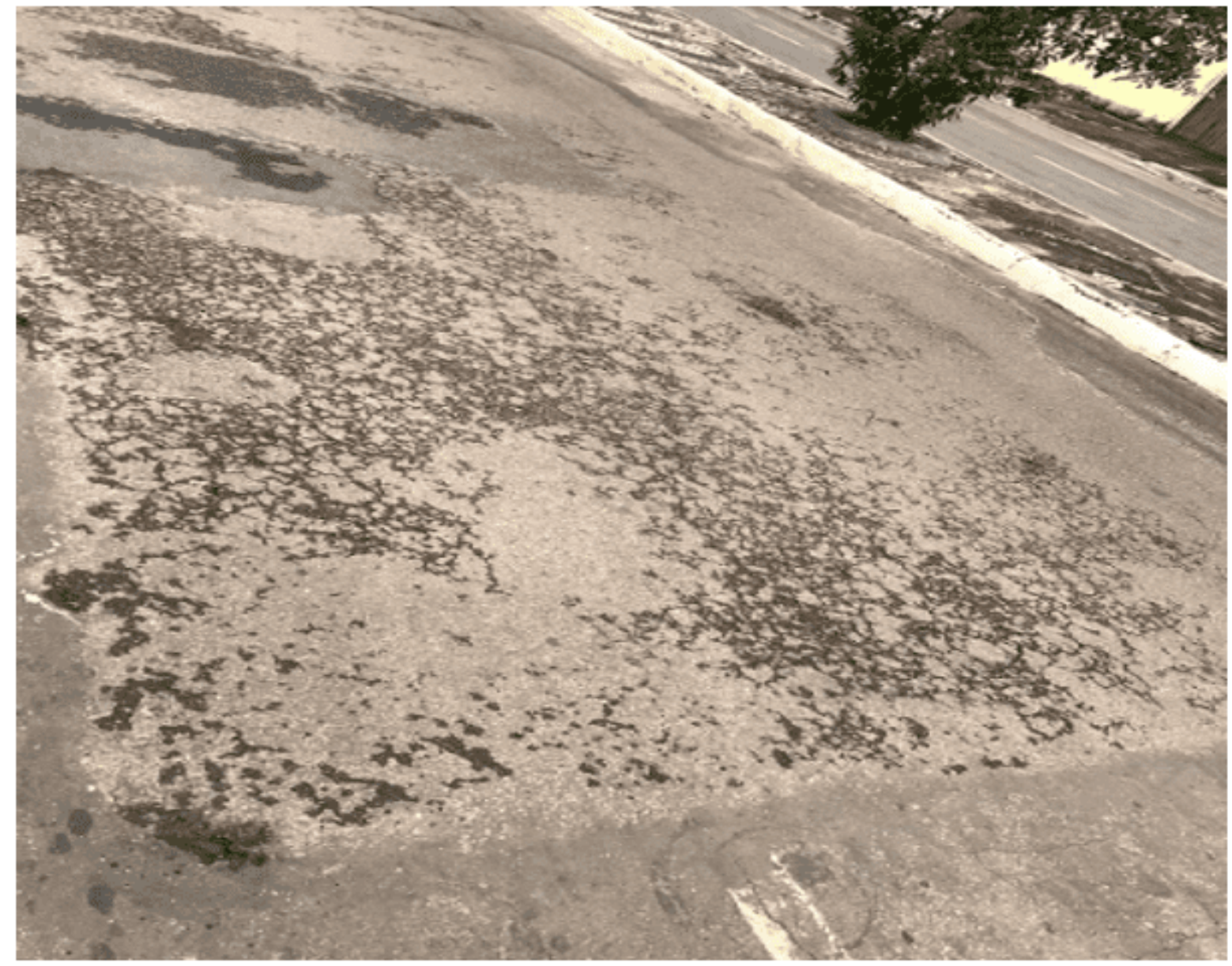

\subsubsection{AFUNDAMENTOS}

Segundo a Novo Asfalto et al. (2017), afundamento é uma deformação permanente com uma depressão na superfície do pavimento, que na maioria das vezes esta acompanhada de solevamento, esta pode se apresentar sob a forma de afundamento plástico ou afundamento de consolidação. A ocorrência do primeiro caso se dá pela influência plástica da(s) camada(s) do pavimento ou do subleito, enquanto o segundo é provocado pela consolidação diferencial dessas camadas. Assim, os afundamentos se classificam em dois tipos: os afundamentos locais (dimensões inferiores à $6 \mathrm{~m}$ ) e afundamentos de trilha de roda (extensões contínuas e maiores que a anterior). 
Conforme a Figura 4 logo abaixo, podem ser observados a presença de várias formas de afundamentos sobre a extensão da via. Na figura 4 (a) esse tipo de patologia pode ser visto uma faixa de asfalto sobre rede e na figura 4 (b), é ilustrado o afundamento causado devido a influência plástica no pavimento.

Figura 4 - Afundamentos
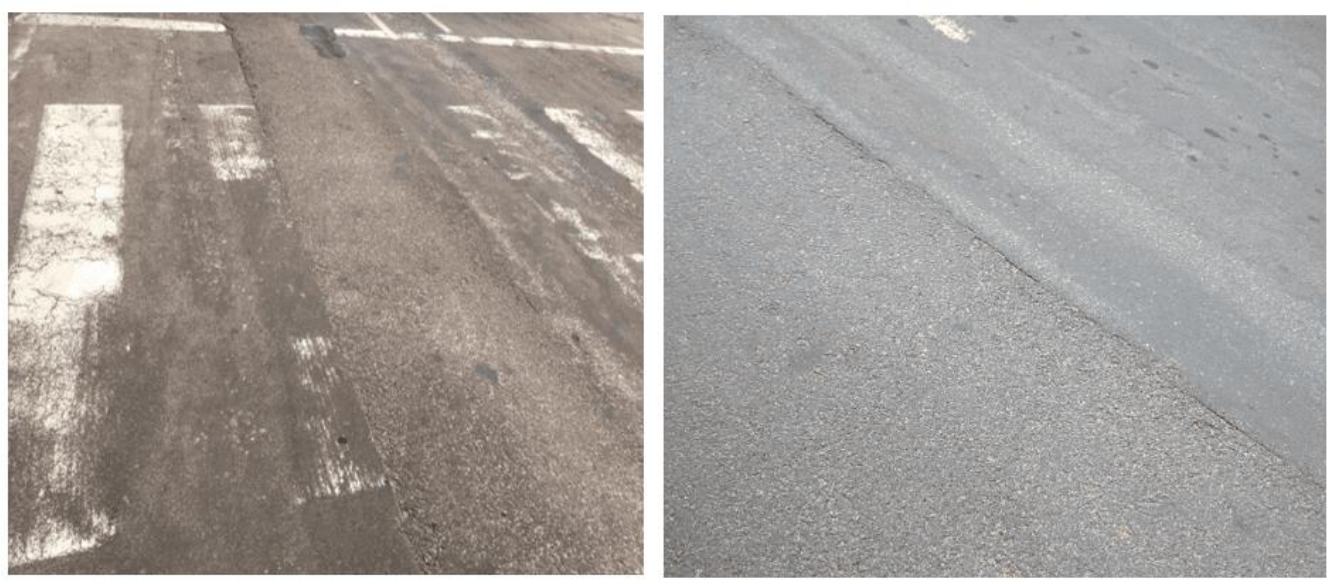

(a) - Sobre o remendo da rede de abastecimento (b) - Afundamento por influência plástica

Fonte: Autor próprio (2020)

\subsubsection{CORRUGAÇÕES OU ONDULAÇÕES TRANSVERSAIS}

O DNIT (2005, p.381), define essas patologias como deformação caracterizada por ondulações ou corrugações transversais de caráter plástico e permanente na superfície do pavimento. E especifica que as prováveis causas dessas ondulações ou corrugações no pavimento são devido à "instabilidade da mistura betuminosa da camada de revestimento e/ou a base de um pavimento; Excesso de umidade das camadas subjacentes; Contaminação da mistura asfáltica por materiais estranhos; Retenção de água na mistura asfáltica".

Essas ondulações descritas acima foram encontradas sobre todo o percurso analisado. Na Figura 5, logo abaixo, é retratado um caso de ondulação encontrado no local. 
Figura 5 - Ondulações sobre a via

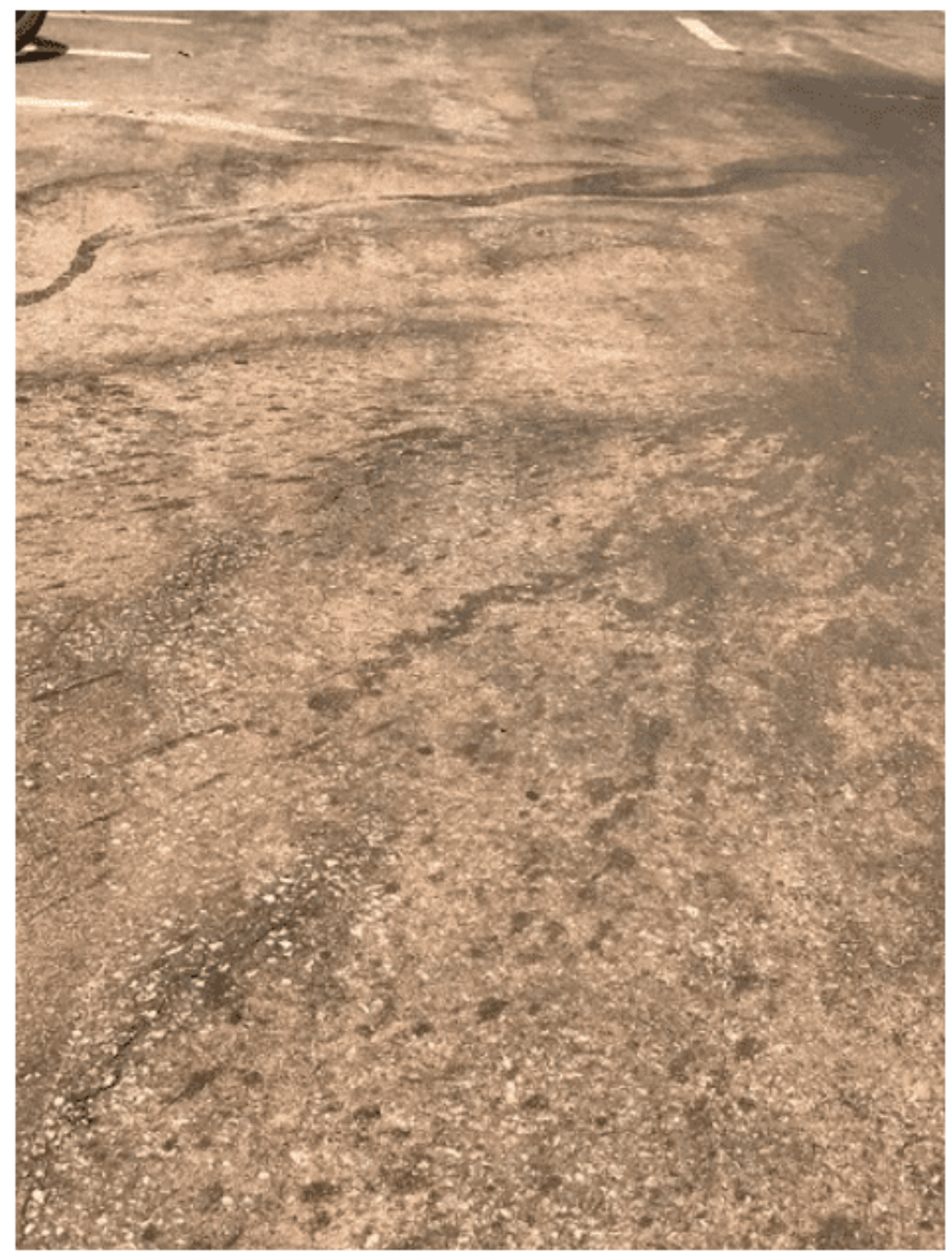

Fonte: Autor próprio (2020)

\subsubsection{EXSUDAÇÃO}

A principal causa da exsudação do asfalto é o excesso de material betuminoso usado no processo de execução dos pavimentos. Normalmente quando a temperatura está elevada, o asfalto tende a sofrer dilatação e esses ligantes são direcionados para a

Disponível em: https://www.nucleodoconhecimento.com.br/engenharia-civil/patologias-asfalticas 
superfície do pavimento, devido à dificuldade de ocupar os espaços vazios no pavimento ou por estarem em excesso.

Em alguns pontos estas patologias não foram apresentadas de forma significativa, entretanto, ainda assim, não deixa de ser um problema em questão. Essa patologia pode ser observada na Figura 6.

Figura 6 - Pontos de exsudação no pavimento

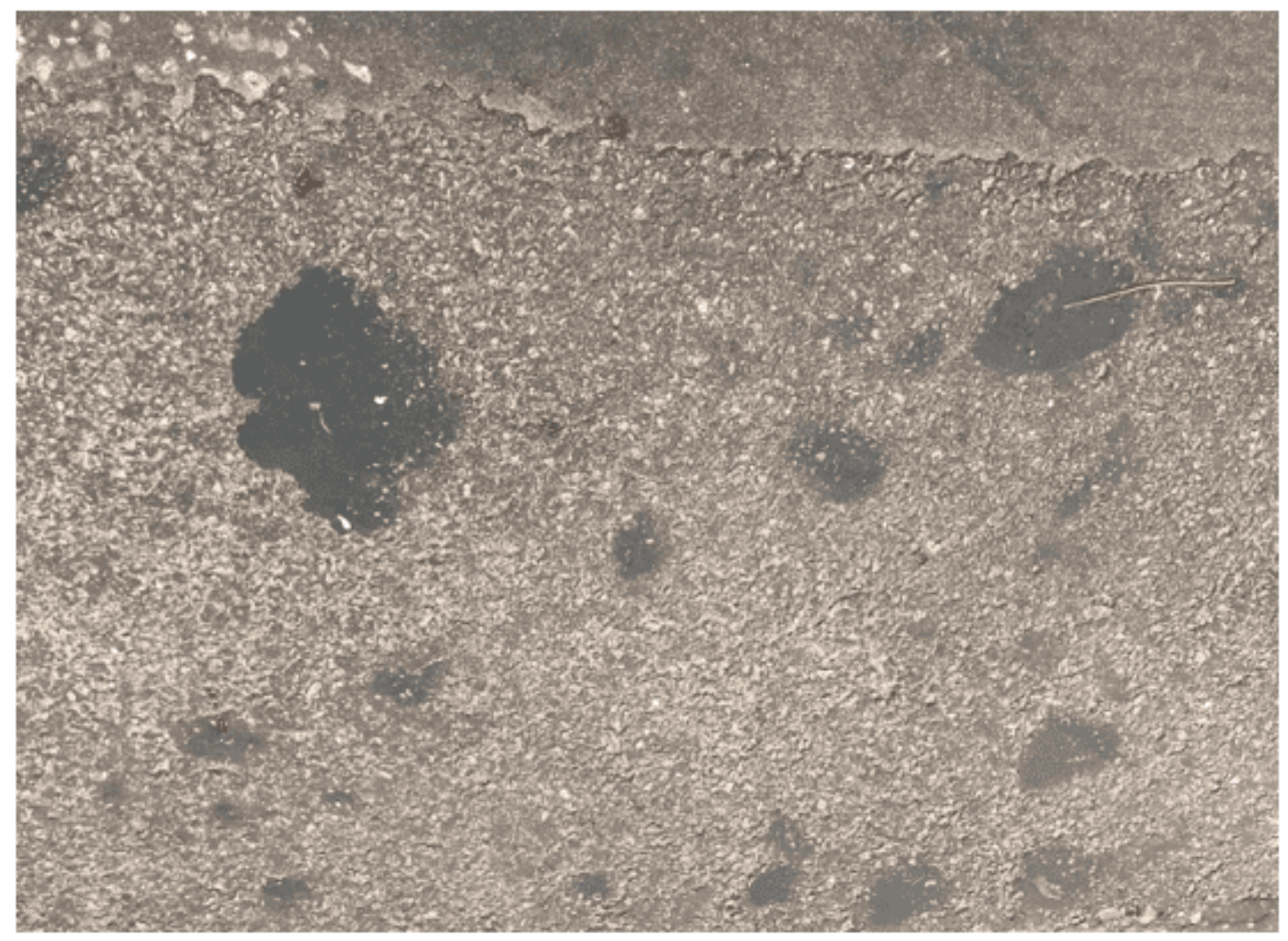

Fonte: Autor próprio (2020)

\subsubsection{DESGASTE OU DESAGREGAÇÃO}

O desgaste é o processo no qual se caracteriza pelo arrancamento progressivo dos agregados presentes no pavimento, com isso causa aspereza na superfície do revestimento. Essa perda de agregados é devido a esforços tangenciais ao pavimento. 
As principais causas dessa patologia estão relacionadas a falha de adesividade entre o ligante e o agregado, presença de água e sobreposição de vazios sobre a camada asfáltica, problemas executivos e também no projeto das misturas que serão utilizados.

O desgaste também tem se apresentado de forma constante sobre a via. Em alguns, casos, chegam a ser bastante crítico do ponto de vista funcional e também estrutural no pavimento. Este caso pode ser observado na Figura 7 (a), na qual é exposto uma situação em um estado crítico e na figura 7 (b), cuja desagregação das partículas do pavimento ocorre sobre a rede de abastecimento.

Figura 7 - Desagregação
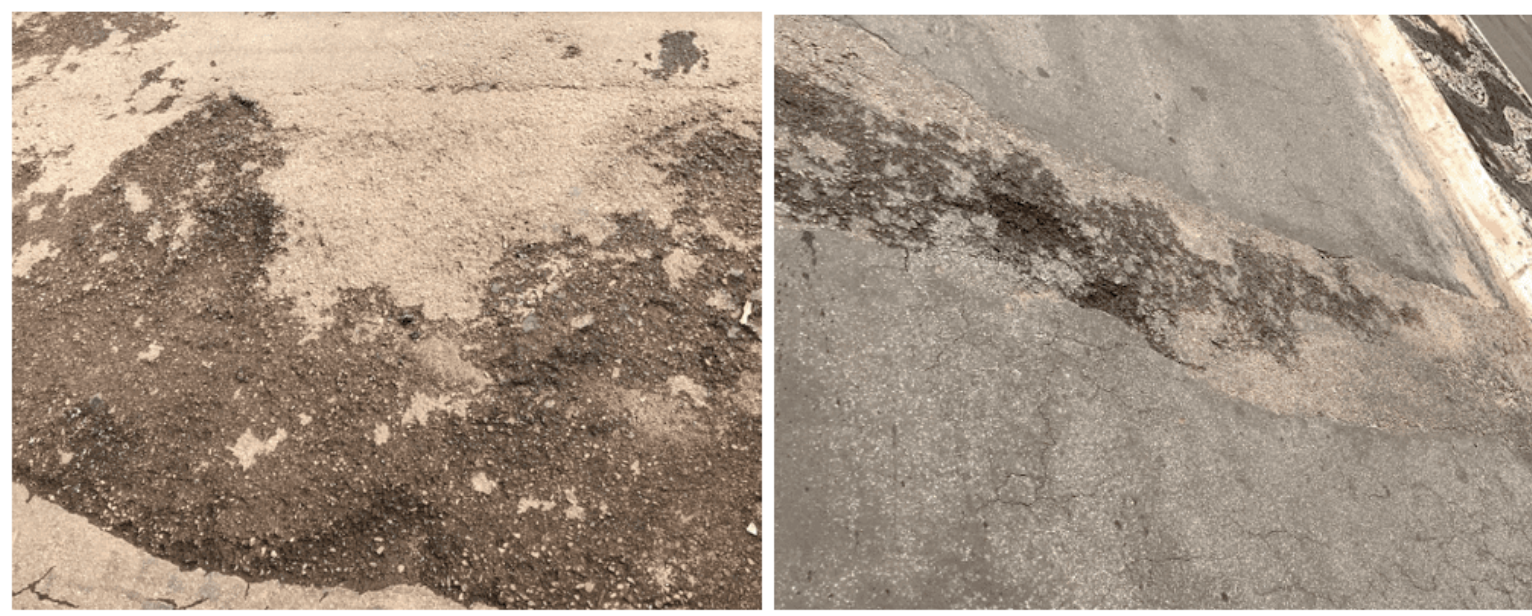

(a) - Desagregação do pavimento (b) - Desagregação sobre a rede

Fonte: Autor próprio (2020)

\subsubsection{BURACOS OU PANELAS}

Os buracos, também denominados de panelas, recebem a seguinte definição:

Os buracos ou panelas são rupturas estruturais localizadas, que está mais enfraquecida do que o seu entorno. Não sendo reparados, rapidamente conduzirão à decomposição dos trechos adjacentes, vindo a comprometer ainda mais seriamente a rodovia (DNIT, 2005, p.321). 
E suas prováveis causas são decorrentes do excesso de cargas sobre o pavimento, da deficiência na elaboração e também na execução do pavimento, e da ação da água devido à infiltração.

Talvez este seja um dos problemas mais comuns em todas as vias do país, devido à falta de manutenção das vias. Embora, em alguns trechos, não fosse tão visível, havia alguns indícios de possíveis surgimento dessas patologias sobre o revestimento asfáltico. Essa patologia pode ser observada na Figura 8.

Figura 8 - Buracos no pavimento

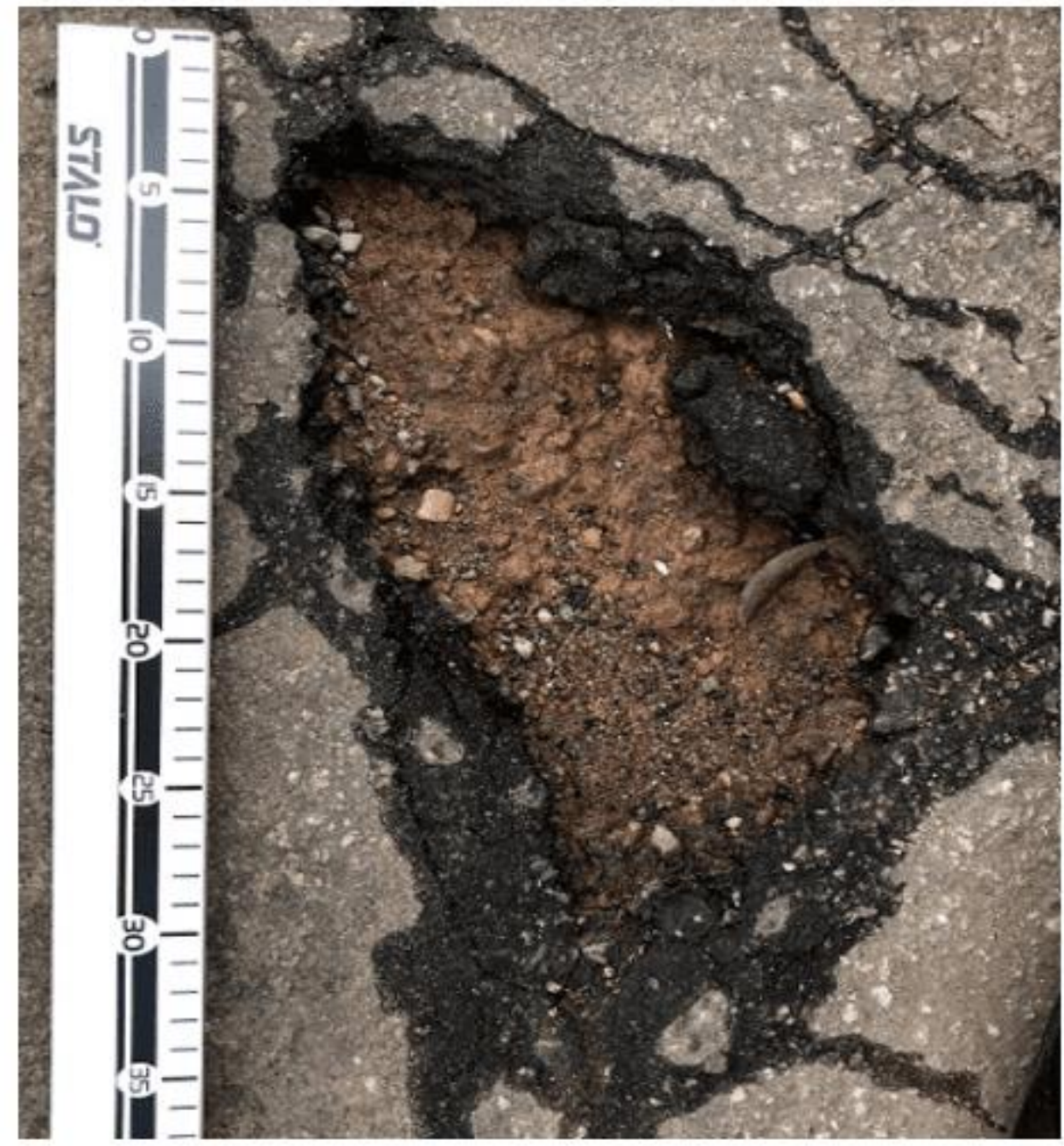

Fonte: Autor próprio (2020) 


\subsubsection{REMENDOS}

Os remendos não são propriamente um defeito, pois estes tratam de um procedimento de correção de buracos ou outras espécies de depressões no pavimento, entretanto quando, não executados de forma adequada, estes podem ocasionar patologias em maiores escalas e também desconforto aos usuários da via.

Em suma, é definido como:

Revestimento onde o material original foi removido e substituído por outro material (similar ou diferente). Remendos existentes são em geral considerados falhas, já que refletem o mau comportamento da estrutura original, gerando normalmente incremento na irregularidade longitudinal (DNIT, 2005, p.385).

As principais causas que deterioram o remendo são tráfego pesado de veículos no local, emprego de materiais de má qualidade, má execução e também devido as ações do meio ambiente. A deterioração de remendos pode ser descrita como um conjunto de danos já existentes, ou seja, devido a fragilidade que se tem no local.

Ao longo da via foram vistos várias situações do emprego do remendo como solução corretiva, entretanto aplicados de maneiras indevidas no pavimento. Esses casos podem ser observados na Figura 9 a seguir. 
Figura 9 - Remendos
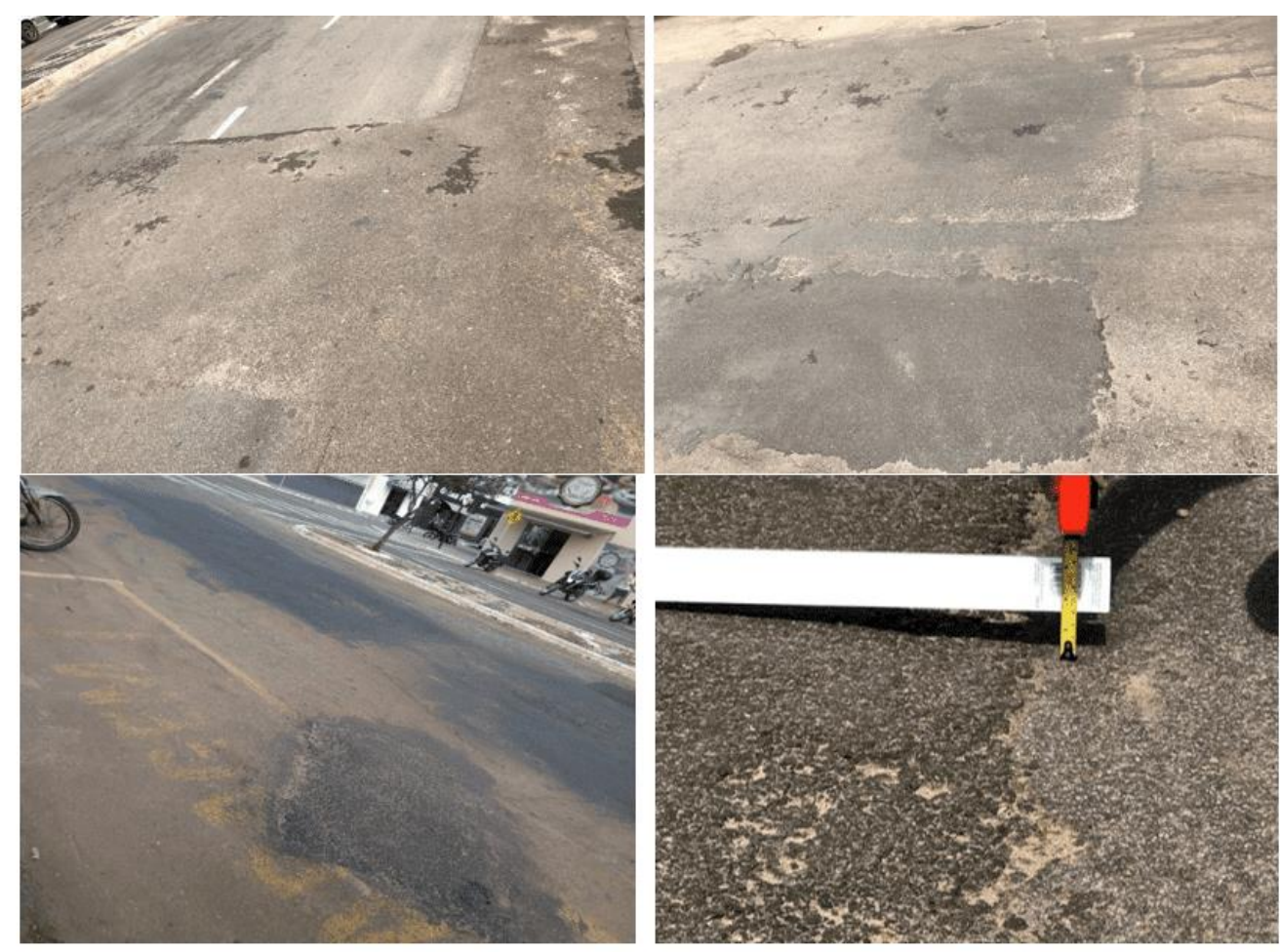

(a) - Remendos das redes (b) - Remendos sobre a via

(c) - Remendos acompanhado com diversas patologias (d) - Mensuração de remendos da via

Fonte: Autor Próprio (2020)

A figura 9 (a) e (b) mostram alguns pontos de remendos na via. Enquanto na figura 9 (c) e (d), mostram o local mais crítico de toda a extensão estudada, na qual pode ser observado vários pontos críticos de remendos e outras patologias abordadas anteriormente e uma mensuração da camada utilizada, respectivamente.

\subsection{SOLUÇÕES}

Devido à grande quantidade de problemas encontradas no pavimento asfáltico da avenida, tem se em questão, possíveis soluções para que tais problemas sejam reparados ou ao menos minimizados.

O tratamento superficial consiste em aplicação de ligantes asfálticos e agregados sem mistura prévia, na pista, com posterior compactação que promove o recobrimento parcial e a adesão entre agregados e ligantes. 
O tratamento conforme a seguinte sequência: ligante é colocado primeiro e agregado depois (BERNUCCI, 2008, p.191).

Dentre as possíveis soluções técnicas podem ser citadas:

- Micro revestimento asfáltico

- Fresagem

- Remendos

\subsubsection{MICRO REVESTIMENTO ASFÁLTICO}

Micro revestimento asfáltico é uma técnica que pode ser considerada uma evolução, pois usa o mesmo princípio e concepção, porém utiliza emulsões modificadas com polímero para aumento a sua vida útil, uma mistura a frio processada em usina móvel especial, de agregados minerais, fíler, água e emulsão com polímero, e eventualmente adição de fibras (BERNUCCI, 2008, p.186).

Figura 10 - Aplicação de micro revestimento

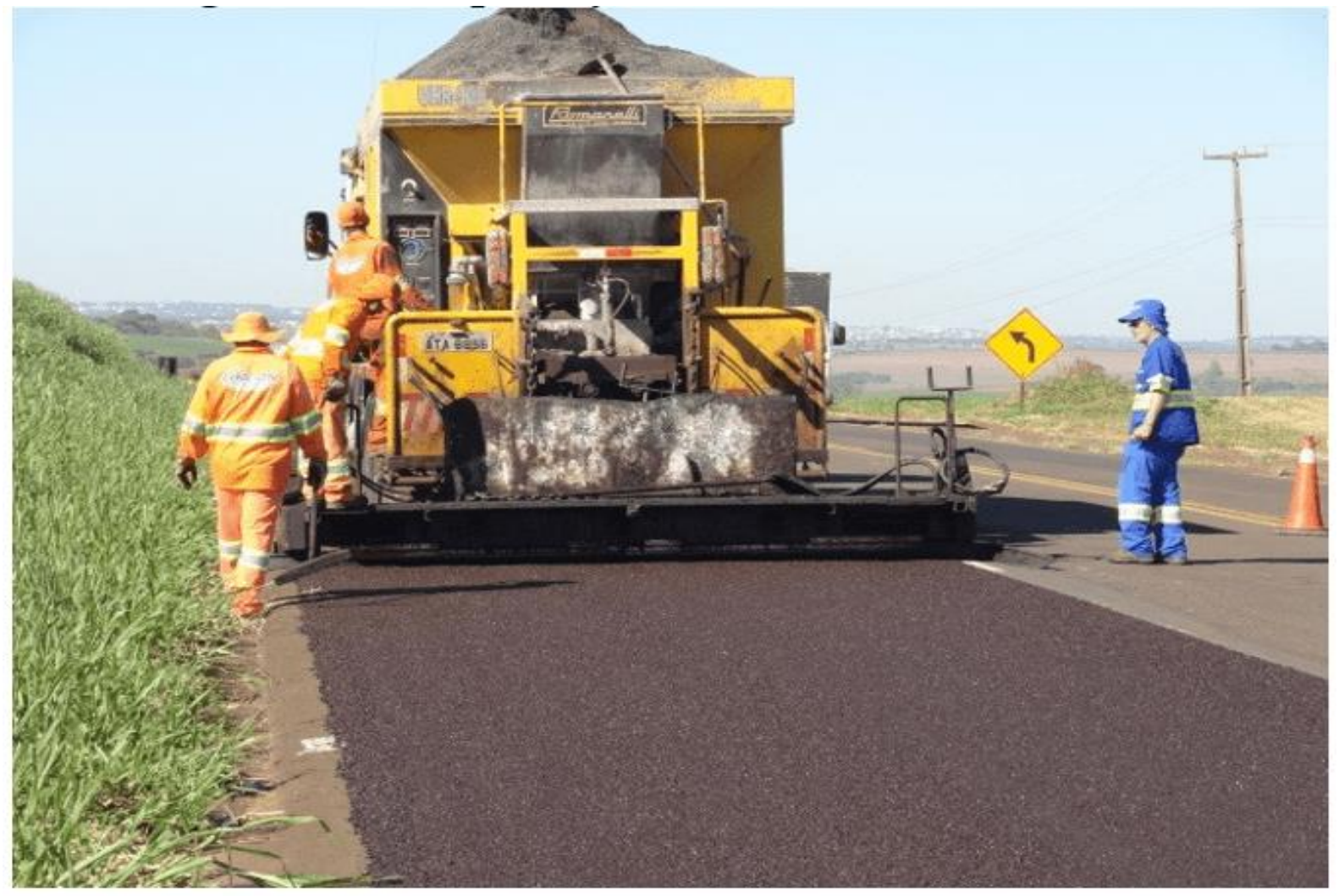

Fonte: Fircon (2020) 


\subsubsection{FRESAGEM}

Segundo Yoshizane (2005), o recapeamento estrutural é a construção de uma ou mais camadas asfálticas sobre o pavimento já existente, e normalmente incluindo uma camada para corrigir o nivelamento do pavimento antigo, seguida de uma camada com espessura uniforme.

Fresagem é a operação de corte, com uso de máquinas especiais, do revestimento asfáltico existente em um trecho de via, ou de outra camada do pavimento, para restauração da qualidade ao rolamento da superfície, ou como melhoramento da capacidade de suporte (BERNUCCI, 2008, p.188).

Figura 11 - Processo de fresagem

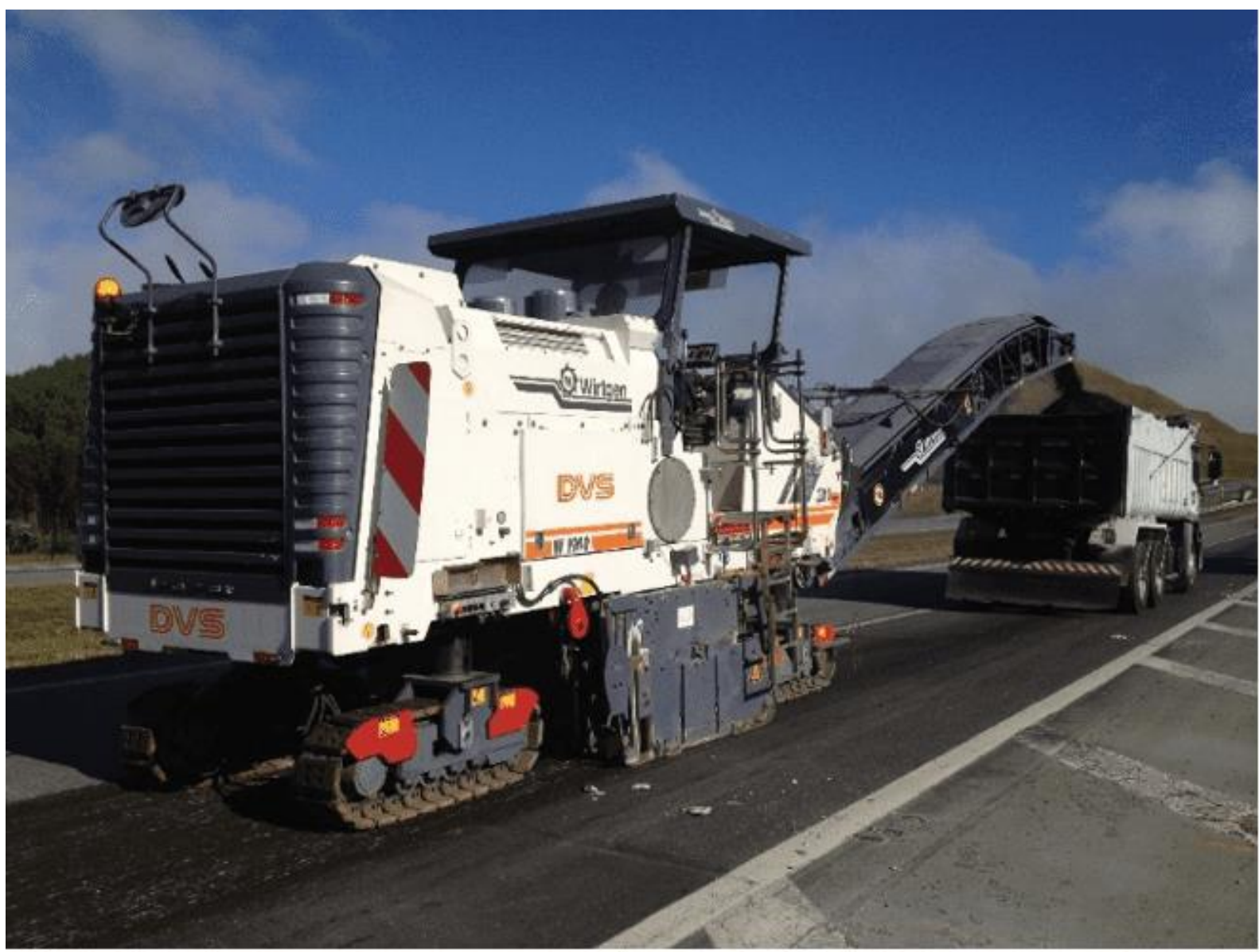

Fonte: DVS Fresagem (2020)

Disponível em: https://www.nucleodoconhecimento.com.br/engenharia-civil/patologias-asfalticas 


\subsubsection{REMENDOS}

De modo geral, todos os pavimentos exigem manutenções em sua estrutura devido aos efeitos constantes do tráfego de veículos e das ações climáticas.

Os remendos constituem o método de reparo mais utilizado na manutenção de rodovias e ruas, porque todos os pavimentos, uma hora ou outra, vão apresentar buracos, resultados do tráfego, de reparos das redes de água, gás, esgoto, telefone, energia elétrica, entre outros (YOSHIZANE, 2005, p.7).

Na execução de remendos em condições climáticas desfavoráveis e em se tratando de remendos emergenciais, é recomendado o uso de prémisturados a frio (PMF). No caso de reparos permanentes é recomendado o uso de CBUQ (ODA, 2003, p.43).

Figura 12 - Correção do pavimento com remendos

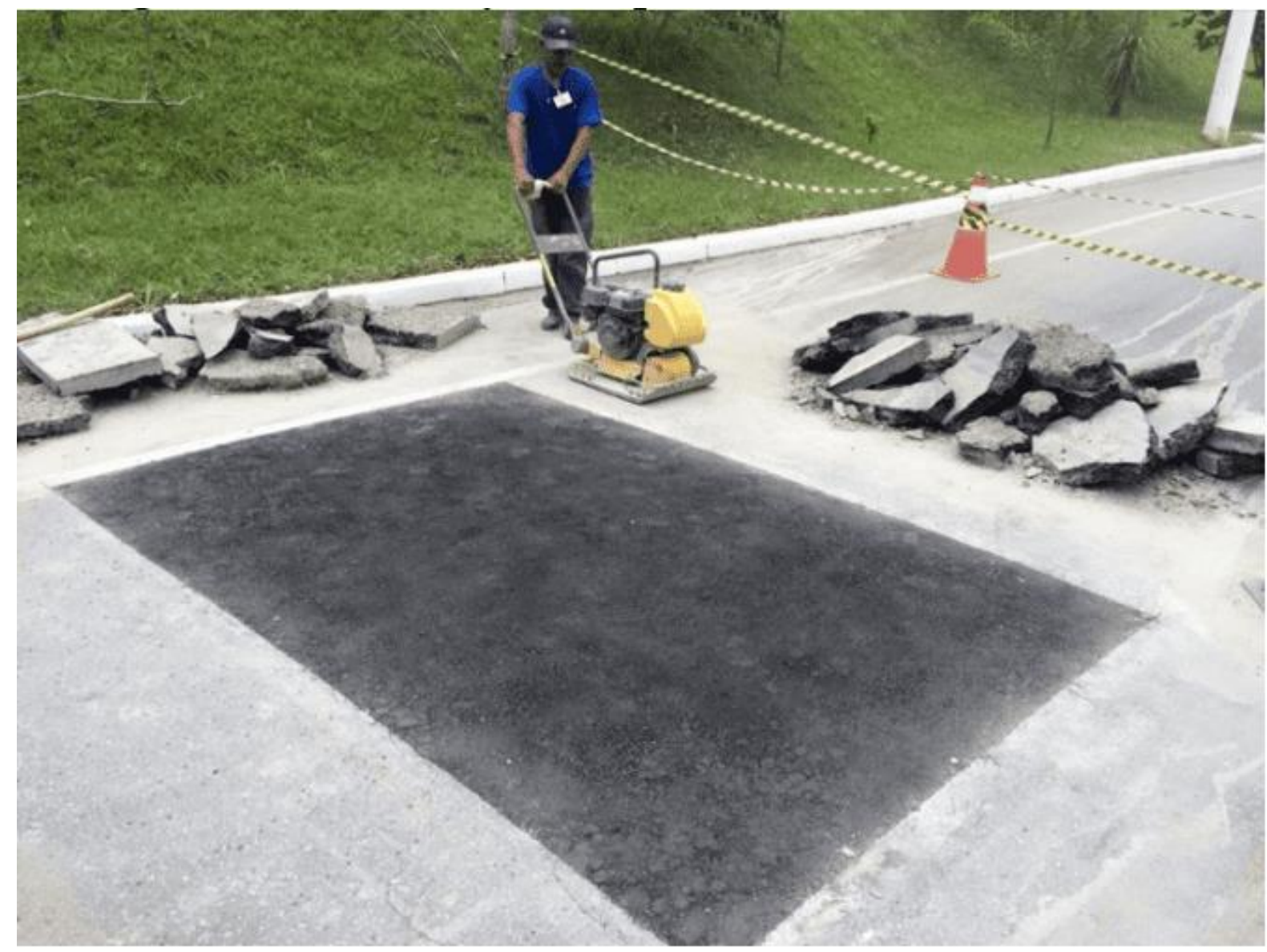

Fonte: Único Asfalto Rio (2020)

Disponível em: https://www.nucleodoconhecimento.com.br/engenharia-civil/patologias-asfalticas 


\section{CONSIDERAÇÕES FINAIS}

Através dos defeitos encontrados, pode-se dizer que uma das principais causas das patologias apresentadas está associado principalmente com o processo construtivo, pois grande parte das patologias foram encontradas nos remendos.

As falhas no processo construtivo que contribuem para o surgimento de patologias estão na má compactação do leito e subleito, e até da própria camada de pavimento asfáltico, na utilização de materiais contaminados, na granulometria dos agregados, relação agregado/ ligante.

A má compactação é a falha mais comum do processo construtivo, no trecho analisado todos os remendos apresentavam essa falha, podendo ser observada na figura 9(d) A má compactação muita das vezes ocorre de forma proposital, deixando de compactar bem na hora da execução do remendo para que o trafego termine de compactar, onde muitas vezes não ocorre e deixa uma ondulação na via causando desconforto aos usuários, ou quando o trafego consegue terminar de compactar, os remendos trincam causando outros tipos de patologia, e por vezes ocorre o afundamento.

$\mathrm{Na}$ maioria dos remendos pode-se notar uma grande disparidade entre as granulometrias dos agregados quando comparados ao do próprio pavimento, algumas vezes com uma granulometria menor, outras vezes maiores. Os remendos com uma grande granulometria dos agregados apresentaram desgaste, onde houve a desagregação de seus agregados, isso ocorre também pelo fator agregado/ ligante, podendo estar associado ao uso insuficiente de ligante. Quando há excesso de ligante no fator agregado/ ligante ocorre a exsudação.

Na chamada "fuga d'água" dos canos de abastecimento, a água que vaza encharca o solo que faz parte das camadas do pavimento asfáltico, assim o solo se encontra contaminado. Na maioria das vezes em que esse sinistro ocorre, a empresa responsável utiliza o mesmo material para reaterrar após a manutenção da 
encanação, desta forma a compactação do remendo fica comprometida devido a utilização de solo saturado, ocasionando o afundamento e trincas nos remendos.

Desta forma, os problemas relacionados a execução, padronização, e utilização de materiais foram os principais motivos para o surgimento de patologias nos remendos ao longo da avenida. Sendo assim, uma execução mais técnica, uma mão de obra mais qualificada, um controle de qualidade seja na compactação dos materiais, como no próprio uso dos materiais, podem tornar os remendos de fato como uma solução, porém os atuais se tornaram um problema as vias. Devido a tantas irregularidades na via, a melhor forma de corrigir tais problemas seria a repavimentação, retirando toda a camada asfáltica e executando uma nova compactação das camadas.

\section{REFERÊNCIAS}

AGUIAR, A.S. et al. Asfalto. Unama, Belém: 2012. Disponível em: $<$ https://pt.scribd.com/doc/95302963/Asfalto-QUIMICA>. Acesso em: 27 de setembro de 2020.

AZAMBUJA, Andrey Reichelt. Pavimento asfálticos: análises de patologias na repavimentação de trechos devido a obras de rede de esgoto sanitário. 2009. Dissertação (Graduação) - Universidade Federal do Rio Grande do Sul. Porto alegre. BALBO, T. JOSÉ. Pavimentação Asfáltica. 3르 ed. Oficina de Textos, 2016.

BERNUCCl et al, L.B. et al. Pavimentação Asfáltica: Formação básica para engenheiros. 1.ed. Rio de Janeiro: Petrobras ABEDA, 2008. Disponível em: $<$ www.proasfalto.com.br> Acesso em: 04 de setembro de 2020.

CALDEIRA et al, M. V. M. et al. Patologias asfálticas na rodovia br-153 na região sul do Tocantins, trecho Cariri - TO / Gurupi - TO, Fortaleza, 2019. Disponível em: $<$

https://semanaacademica.org.br/system/files/artigos/patologias_asfalticas_na_rodovi a_br-153_na_regiao_sul_do_tocantins_techo_cariri-togurupi-to.pdf >. Acesso em 04 de setembro de 2020. 
DEPARTAMENTO NACIONAL DE INFRA-ESTRUTURA DE TRANSPORTES. DNIT 005/2003 - TER: Defeitos nos pavimentos flexíveis e semi-rígidos. Rio de Janeiro: IPR, 2003. 12 p. $\quad$ Disponível em: http://ipr.dnit.gov.br/normas/DNIT005_2003_TER.pdf >. Acesso em: 06 de setembro de 2020.

DIRETORIA DE PLANEJAMENTO E PESQUISA / IPR. Defeitos nos pavimentos flexíveis e semirrígidos - Terminologia. NORMA DNIT 005/2003 - TER. Disponível em:

http://ipr.dnit.gov.br/normas-e-manuais/normas/terminologiater/dnit005_2003_ter.pdf. Acesso em: 08 de setembro de 2020.

EQUIPAMENTOS, Fresagem, 2020. Disponível em: < http://fresagem.com.br/equipamentos/fresadora-w200/>. Acesso em: 04 de setembro de 2020.

GUILHERME et al. Deize Daiane Pinto et al, Avaliação funcional do pavimento flexível: estudo de caso - trecho da rodovia RN-016. Disponivel em: $<$ https://confea.org.br/sites/default/files/antigos/contecc2017/civil/45_afdpfedctdrr.pdf >. Acesso em 22 de setembro de 2020.

INDEX, Único Asfaltos Rio, 2020. Disponível em: <http://unicoasfaltosrio.com.br/index.html>. Acesso em: 04 de setembro de 2020.

MARCATO et al., V. D. et al. Manifestações patológicas em estruturas asfálticas: estudo de caso na rodovia MG-190. Disponível em: $<$ http://repositorio.fucamp.com.br/bitstream/FUCAMP/522/1/manifestacoespatologica sem.pdf>. Acesso em: 04 de setembro de 2020.

MICRO REVESTIMENTO ASFÁlTICO, Fircon, 2020. Disponível em: <http://www.fircon.com.br/nossos-produtos/643/micro-revestimento-asfaltico-a-frio>. Acesso em: 04 de setembro de 2020. 
NOVO ASFALTO. Patologias em pavimento asfáltico. Disponível em: <https://novoasfalto.files.wordpress.com/2017/04/ebook-patologias-em-pavimentoasfc3a1ltico-completo.pdf>. Acesso em 27 de setembro de 2020.

PRESTES, Marilez Pôrto. Métodos de avaliação visual de pavimentos flexíveis Um estudo comparativo. Dissertação (Engenharia dos transportes) - Universidade Federal Do Rio Grande Do Sul, Porto Alegre, 2001.

RÖHM, S.A. Consideração sobre penetrômetros dinâmicos leves aplicados na construção e avaliação de pavimentos de baixo custo. 1984. Dissertação (Mestrado) - Escola de Engenharia de São Carlos, Universidade de São Paulo, São Carlos.

SILVA et al, Cristiano de Araújo et al. Estudo de caso de patologias em pavimento flexível em rodovia do oeste do paraná, Toledo, 2018. Disponível em: https://tcc.unipar.br/files/tccs/31eeb2453bac65658d407b2332be764f.pdf Acesso em: 04 de setembro de 2020.

TIPOS DE PATOLOGIA DO ASFALTO EM RODOVIAS, Dynatest, 2017. Disponível em: <http://dynatest.com.br/tipos-de-patologia-do-asfalto-em-rodovias/>. Acesso em 05 de setembro de 2020.

YOSHIZANE, Prof. Hiroshi Paulo. Defeitos, Manutenção e Reabilitação de Pavimento Asfáltico. Universidade Estadual de Campinas, Centro Superior de Educação Tecnológica CESET, Limeira, 2005.

Enviado: Setembro, 2020.

Aprovado: Outubro, 2020. 